REVIEW

MECHANISMS IN ENDOCRINOLOGY

\title{
Ghrelin: the differences between acyl- and des-acyl ghrelin
}

\author{
Patric J D Delhanty, Sebastian J Neggers and Aart J van der Lely \\ Department of Medicine, Erasmus University MC, PO Box 2040, 3000 CA Rotterdam, The Netherlands \\ (Correspondence should be addressed to A J van der Lely; Email: a.vanderlelij@erasmusmc.nl)
}

\begin{abstract}
Des-acyl ghrelin (DAG) is one of the three preproghrelin gene-encoded peptides. Compared with ghrelin and obestatin, it has not received the attention it deserves. DAG has long been considered an inert degradation product of acyl ghrelin (AG). Recent evidence, however, indicates that DAG behaves like a separate hormone. DAG can act together with AG, can antagonize AG, and seems to have AG-independent effects. Therefore, it is believed that DAG must activate its own receptor and that it may also interact with AG at this receptor. Of potential clinical importance is that an increasing number of studies suggest that DAG might be a functional inhibitor of ghrelin and that DAG can suppress ghrelin levels in humans. Therefore, DAG or DAG analogs might be good candidates for future treatment of metabolic disorders or other conditions in which antagonism of AG actions could be beneficial, such as diabetes, obesity, and Prader-Willi syndrome.
\end{abstract}

European Journal of Endocrinology 167 601-608

\section{Introduction}

It is now more than 12 years since ghrelin was identified as the ligand of the $\mathrm{GH}$ secretagogue receptor type 1a (GHSR1a). The story of des-acyl ghrelin (DAG; Fig. 1) also began in 1999, when Kojima et al. described this peptide in the same report that introduced ghrelin to the scientific world $(1,2)$. The preproghrelin gene-derived peptides include acyl ghrelin (AG), DAG, and obestatin. AG is produced mainly by the stomach and exerts its central and peripheral effects through GHSR1a (1). The ghrelin peptide is acylated by the enzyme ghrelin $O$-acyl transferase (GOAT) (3, 4, 5), which is expressed predominantly in the stomach, gut, and pancreas but also at other sites (6).

The concept that emerged from Kojima's paper and many others was that DAG should be considered as the degradation product of ghrelin without biological activities. The obvious reason for this is that DAG is unable to bind and activate the GHSR1a in the submicromolar, physiological range $(1,7)$. Therefore, DAG has never received the level of attention in research and the literature that it deserves, although a growing number of reports strongly suggest that DAG has intrinsic activities in a variety of physiological and pathophysiological situations. Depending on the experimental circumstance, DAG can either antagonize or support the activities of ghrelin, while in other situations, DAG works completely independently of ghrelin.

In this review, we will try to address some of these actions of DAG on (patho)physiological processes.
We describe the properties of DAG not only as a functional antagonist of $\mathrm{AG}$ but also as a strong inhibitor of $A G$ serum levels in vivo in animals and men. Finally, we will describe the situations in which DAG acts independently of AG.

\section{The controversial aspects of the AG/DAG ratio}

Although available data are still contradictory, several studies have indicated that obese mice and humans might have lower DAG levels than normal-weight subjects whereas AG levels are similar, indicating that obesity could reflect a relative DAG deficiency and that DAG levels might be regulated by body weight $(8,9,10)$. Moreover, insulin-resistant obese subjects have an elevated AG/DAG ratio when compared with insulinsensitive obese subjects $(11,12)$. St-Pierre et al. (9) found that the dysregulation of ghrelin secretion profiles during a euglycemic/hyperinsulinemic clamp (EHC) is associated with insulin resistance (IR). They determined whether insulin-sensitive overweight or obese (ISO) and insulin-resistant overweight or obese (IRO) individuals display different AG and DAG profiles during a EHC in 89 nondiabetic overweight and obese postmenopausal women. DAG levels were found to be significantly decreased for ISO and IRO individuals during the EHC, whereas only ISO subjects displayed a significant reduction of $\mathrm{AG}$ levels. Also, the ratio of $\mathrm{AG} / \mathrm{DAG}$ 


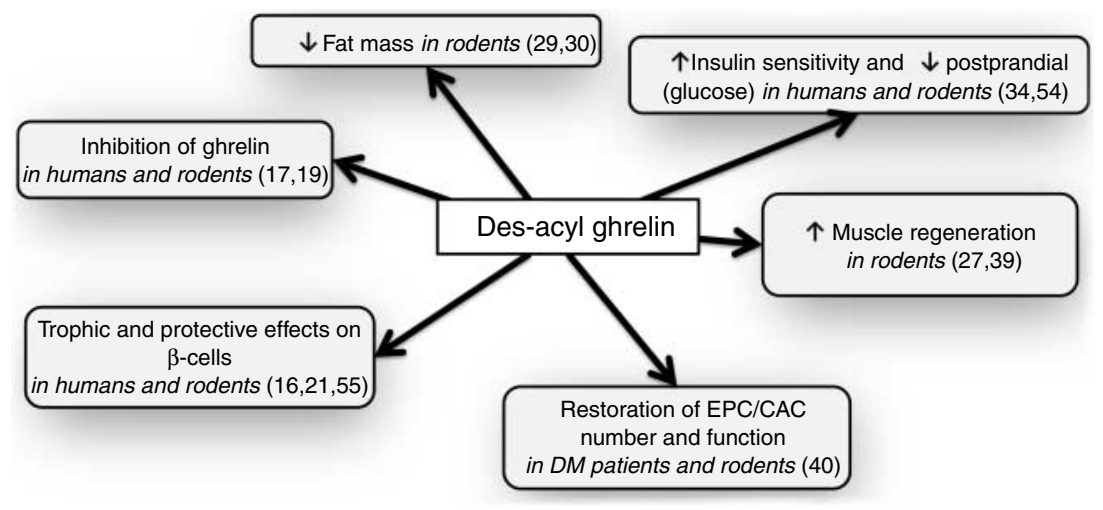

Figure 1 Overview of des-acyl ghrelin actions, along with some references for further reading. (fasting and area under the curve (AUC)) was significantly decreased in ISO individuals (11).

Rodriguez et al. found that AG levels were increased, whereas DAG levels were decreased in obesity and obesity-associated type 2 diabetes. Body mass index, waist circumference, insulin, and homeostasis model assessment (HOMA) index were positively correlated with AG levels (13). However, it is noteworthy that in the latter study, blood samples were not collected in a way that prevents de-acylation of ghrelin; therefore, the data must be interpreted with caution.

Barazzoni et al. determined potential differential associations of ghrelin isoforms with IR and the impact of obesity on their plasma concentrations in 45 subjects with metabolic syndrome. Plasma insulin and HOMAIR were negatively associated with DAG but positively with $A G$ and AG/DAG ratios. Compared with the nonobese, obese metabolic syndrome patients had lower DAG but comparable AG and higher AG/DAG ratios. Apparently, obesity could alter circulating ghrelin profiles, and a relative AG excess or DAG deficiency can contribute to obesity-associated IR in metabolic syndrome (12).

Finally, Prader-Willi syndrome (PWS) is a leading genetic cause of obesity, characterized by hyperphagia, endocrine, and developmental disorders. It is believed that the hyperphagia results from impaired gut hormone signaling. Purtell et al. reported that compared with adiposity-matched controls, hyperphagia in PWS is not related to a lower postprandial glucagon-like peptide-1 or peptide YY response. However, elevated ghrelin levels in PWS did show a relation with increased hunger, which was unrelated to insulin levels (14).

Goldstone et al. investigated whether differences in appetite hormones may explain the development of abnormal eating behavior in 42 young ( 7 months-5 years) children with PWS. No significant relationship was found between eating behavior and the levels of any of the hormones measured or IR, independent of age. However, even in these young children, PWS was associated with low levels of the anorexigenic pancreatic polypeptide (PP), as has been described in older children and adults. Only later in life do hyperghrelinemia or hypoinsulinemia begin to contribute to the hyperphagia of PWS (15). It was hypothesized that abnormal development or sensitivity of pathways required for activity of these appetitive hormones (e.g. in the CNS) may be responsible for the emergence of hyperphagia in PWS.

\section{DAG is a functional ghrelin antagonist}

\section{The first indications}

It was the group of Broglio et al. (16) that shifted the existing paradigm by suggesting that DAG should be considered as a separate hormone. Others later supported their findings. Broglio et al. studied the interaction of the combined administration of AG and DAG in six normal young volunteers. As expected, AG administration alone markedly increased circulating $\mathrm{GH}$, prolactin, ACTH, and cortisol levels. AG administration was also followed by a decrease in insulin levels and an increase in plasma glucose levels. While DAG administration alone had no effects, DAG together with AG diminished the insulin and glucose response to AG. Their findings indicated for the first time that DAG can be metabolically active by counteracting the effects of AG on insulin secretion and glucose metabolism.

Inhoff et al. (17) have also shown that the metabolic effects of AG (administered i.p.) could be abrogated by coadministered DAG in nonfasted rats. DAG alone did not alter food intake, as was also reported by others, as, e.g. by Neary et al. (18). Double labeling revealed that nesfatin-1 immunoreactive neurons in the arcuate nucleus are activated by simultaneous injection of AG and DAG. These results suggest that DAG suppresses AG-induced food intake by preventing the increase in neuronal activity in the arcuate nucleus and recruiting nesfatin-1 immunopositive neurons (17). Kumar et al. also reported the antagonistic properties of DAG on AG (19).

By using isolated mouse pancreatic islets, they studied suppression of spontaneous secretion of PP by AG and obestatin. Interestingly, the PP-releasing effect of AG, but not obestatin, was counteracted by coadministration of DAG. Apparently, AG and obestatin inhibit spontaneous PP secretion at physiologically 
relevant concentrations by acting through separate receptors (19).

Gauna et al. (20) reported that administration of AG in humans reduces insulin sensitivity, whereas the combination of AG plus DAG strongly improves insulin sensitivity. They studied the effects of acute administration of AG, DAG, and their combined administration in eight adult-onset $\mathrm{GH}$-deficient patients. AG, which was rapidly cleared from the circulation, induced a rapid rise in glucose and insulin levels. AG and DAG coadministration, however, prevented the AG-induced rise in insulin and glucose. Moreover, cotreatment with DAG prevented AG-induced IR for at least $6 \mathrm{~h}$ after administration (20).

\section{In vitro studies}

Granata et al. (21) investigated the role of AG in pancreatic $\beta$-cell proliferation as well as apoptosis induced by serum starvation or cytokine (interferon $\gamma /$ tumor necrosis factor $\alpha$ ) treatment. They found that HIT-T1 5 cells (a hamster insulinoma cell line) expressed Ghrl but not the GHSR 1a mRNAs. However, both DAG and AG recognized common high-affinity binding sites on these cells. Furthermore, both AG and DAG stimulated insulin secretion by these cells.

Interestingly, both DAG- and AG-induced cell survival and protection against apoptosis in isolated human islets of Langerhans. Insulin-positive $\beta$-cells in these islets expressed GHSR 1a, explaining the mechanism of action for AG. However, competitive binding studies using radiolabeled DAG suggest that islets also express DAG and AG binding sites that are probably not the classical GHSR1a. Therefore, the effects of DAG and AG may also occur via mechanisms independent of the GHSR 1a, likely mediated by specific AG and DAG binding sites (21).

Another indication that DAG acts as an AG antagonist was demonstrated by Gauna et al. (22). They reported that AG stimulates, whereas DAG inhibits glucose output by primary hepatocytes. AG, but not the $\mathrm{GH}$ secretagogue hexarelin, dose dependently induced glucose output. However, DAG dose dependently inhibited glucose release and completely reversed AG-induced glucose output. Interestingly, GHSR 1a gene expression was not detectable in the hepatocyte preparations. The observed effects of DAG, in the absence of GHSR 1a expression and lack of a response to hexarelin treatment, again indicate the involvement of an uncharacterized ghrelin receptor (sub)type (22).

More recently, Miegueu et al. (23) reported the direct effects of ghrelin gene family peptides on preadipocyte proliferation, differentiation, and adipocyte lipid and glucose metabolism in 3T3-L1 cells. In these adipocytes, fatty acid (FA) uptake was increased at sub-nanomolar concentrations in a concentration-dependent manner by obestatin and DAG, in particular. Interestingly, DAG stimulation of FA uptake was blocked by the
[D-Lys3]-GHRP-6, which suggests that this GHSR1a antagonist (although not very selective for the GHSR1a $(24,25))$ can block the hypothetical DAG receptor as well (23). An independent report on the effects of AG and DAG in adipocytes by Rodriguez et al. (13) also shows that AG and DAG can stimulate lipid accumulation in human visceral adipocytes.

In agreement with earlier studies in primary adipocytes (26), DAG and obestatin significantly decreased lipolysis. Baragli et al. (27) also reported that AG and DAG block isoproterenol and forskolininduced lipolysis; a process in which phosphodiesterase (PDE) seems to be involved. In line with this, cilostamide, a specific PDE3B inhibitor, blocked the effects of $A G$ and DAG on isoproterenol-induced lipolysis. In particular, selective inhibition of PI3K iso-enzyme $\gamma$ prevented AG and DAG effects on isoproterenol-stimulated lipolysis, impeding AKT phosphorylation (Table 1) (27).

Lear et al. (28) also reported that DAG has specific binding sites and different metabolic effects in the murine HL-1 adult cardiomyocyte cell line. They compared the effects of AG and DAG on glucose and FA uptake and attempted to identify DAG-specific binding sites in cardiomyocytes. AG and DAG had opposing metabolic effects: DAG increased mediumchain FA uptake, whereas neither $A G$ alone nor in combination with DAG did so. In HL-1 cells and primary cultures of neonatal rat cardiomyocytes, DAG but not AG increased insulin-induced translocation of glucose transporter-4 from nuclear to cytoplasmic compartments. HL-1 and primary-cultured mouse and rat cardiomyocytes each possessed two independent, specific, binding sites for DAG that were not recognized by AG. Neither AG nor DAG affected cell viability, whereas both isoforms were equally protective against apoptosis. Apparently, in cardiomyocytes, DAG binds to specific receptors and has effects on glucose and medium-chain FA uptake that are distinct from those of AG (28).

Moazed et al. (29) also suggested the presence of a non-GHSR 1a that transduces DAG signals. They reported that DAG evokes endothelium-dependent vasodilatation of rat mesenteric vascular bed via activation of potassium channels. However, this vasodilator response in the perfused rat mesenteric vascular bed was not mediated by the classical GHSR1a (29).

\section{In vivo results in rodents}

In 2005, Asakawa et al. (30) reported that DAG appeared to decrease food intake and gastric emptying rate through actions on the hypothalamus. DAG transgenic mice exhibit a decrease in body weight, food intake, and fat pad mass accompanied by moderately decreased linear growth, along with a decrease in gastric emptying. This again indicates, but now in vivo, that in contrast to $\mathrm{AG}$, DAG induces 
Table 1 Summary of in vivo and in vitro study results of DAG effects in animals and in humans

\begin{tabular}{|c|c|c|c|c|}
\hline Reported observations in which DAG effects were found & $\begin{array}{l}\text { In vitro } \\
\text { animal } \\
\text { studies }\end{array}$ & $\begin{array}{l}\text { In vivo } \\
\text { animal } \\
\text { studies }\end{array}$ & $\begin{array}{l}\text { In vitro } \\
\text { human } \\
\text { studies }\end{array}$ & $\begin{array}{l}\text { In vivo } \\
\text { human } \\
\text { studies }\end{array}$ \\
\hline $\begin{array}{l}\text { DAG has specific binding sites and different metabolic effects in the murine } \\
\text { HL-1 adult cardiomyocyte cell line }\end{array}$ & $(27)$ & & & \\
\hline $\begin{array}{l}\text { DAG dose dependently inhibits glucose release and reverses ghrelin-induced } \\
\text { glucose output in primary porcine hepatocytes }\end{array}$ & $(22)$ & & & \\
\hline $\begin{array}{l}\text { Direct effects of ghrelin gene family peptides on preadipocyte proliferation, } \\
\text { differentiation, and adipocyte lipid and glucose metabolism in 3T3-L1 cells }\end{array}$ & $(23)$ & & & \\
\hline $\begin{array}{l}\text { DAG can improve cell survival and provide protection against apoptosis in isolated } \\
\text { islets of Langerhans }\end{array}$ & $(21,56)$ & & $(21)$ & \\
\hline DAG probably has its own receptor(s) & & $(5,36-38)$ & & \\
\hline $\begin{array}{l}\text { DAG evokes GHSR1a-independent endothelium-dependent vasodilatation of rat } \\
\text { mesenteric vascular bed via activation of potassium channels }\end{array}$ & $(28)$ & & & \\
\hline Both ghrelin and DAG can block isoproterenol and forskolin-induced lipolysis & (26) & & & \\
\hline $\begin{array}{l}\text { DAG exhibits pro-anabolic and anticatabolic effects on } \mathrm{C} 2 \mathrm{C} 12 \text { myotubes exposed } \\
\text { to cytokines and reduces burn-induced muscle proteolysis in rats }\end{array}$ & (39) & & & \\
\hline The metabolic effects of ghrelin can be abrogated by coadministration of DAG & & $(17,19)$ & & $(57,58)$ \\
\hline Insulin-resistant obese subjects have an elevated ghrelin/DAG ratio & & & & $(11,12)$ \\
\hline Obese mice and humans have lowered DAG levels & & $(8,9)$ & & $(10)$ \\
\hline DAG can decrease food intake and gastric emptying rate via the hypothalamus & & (29) & & \\
\hline $\begin{array}{l}\text { In the presence of high DAG levels, fat masses decrease in FABP4-ghrelin } \\
\text { transgenic mice that become resistant to obesity induced by high-fat diet }\end{array}$ & & (30) & & \\
\hline $\begin{array}{l}\text { I.v. DAG administration improves glucose metabolism and inhibits lipolysis in } \\
\text { healthy volunteers }\end{array}$ & & & & $(34)$ \\
\hline $\begin{array}{l}\text { In obesity and obesity-associated type } 2 \text { diabetes, ghrelin levels are increased and } \\
\text { DAG levels decreased }\end{array}$ & & & & (13) \\
\hline DAG administration strongly inhibits ghrelin levels & & Ozcan et al.* & & \\
\hline $\begin{array}{l}\text { Improvements in body weight and body composition are associated with an increase } \\
\text { in DAG }\end{array}$ & & & & $(35)$ \\
\hline DAG can rescue endothelial progenitor cell function in individuals with type 2 diabetes & & (40) & & (40) \\
\hline
\end{tabular}

negative energy balance by decreasing food intake and delaying gastric emptying (30).

Following on from the study of Asakawa et al., Zhang et al. studied the effects on adiposity and glucose metabolism of overexpressing DAG in the fat depots of mice, using the FA-binding protein-4 (FABP4) promoter to drive expression of a murine preproghrelin transgene (31). In the presence of high DAG levels, epididymal and perirenal fat masses decreased. FABP4-ghrelin transgenic mice appeared to be resistant to obesity induced by high-fat diet. Glucose tolerance tests showed significantly faster clearance of glucose in FABP4-ghrelin transgenic mice than in controls. Insulin sensitivity testing showed that FABP4-ghrelin transgenic mice had a significantly greater hypoglycemic response to insulin, indicating markedly improved insulin sensitivity (31). As the FABP4 promoter is also active in the hypothalamus (32), it is very likely that FABP4-ghrelin transgenic mice overexpress DAG in the hypothalamus as well and that part of the effect may be through actions of DAG at a central level. Several other studies, however, could not find an appetite-inhibiting effect of DAG (e.g. Inhoff et al. (17) and Neary et al. (18)).

The potential clinical importance of inhibiting AG has recently been reported in rodents. Barnett et al. (33) reported the design, synthesis, and characterization of
GO-CoA-Tat, a peptide-based bi-substrate analog that antagonizes GOAT. I.p. administration of GO-CoA-Tat improved glucose tolerance and reduced weight gain in wild-type (WT) mice. Interestingly, they did not observe this reduction in weight gain in ghrelin-deficient mice that lack both AG and DAG. Apparently, GO-CoA-Tat administration reduces weight gain provided that the ghrelin gene is still present (so ghrelin effect is low and DAG effect is present) and that in ghrelin $\mathrm{KO}$ mice this weight reducing effect of GO-CoA-Tat administration is lost (so both ghrelin and DAG effects are low). This might suggest that the presence of DAG is at least partly responsible for the inhibition in weight gain (as acyl ghrelin effects are already low due to the GO-CoA-Tat administration).

With regard to the effects of GO-CoA-Tat administration on insulin sensitivity, the situation might be different. Barnett et al. also reported that WT mice that received an intraperitoneal glucose challenge (ipGTT) after pre-treatment with GO-CoA-Tat showed a significant increase in insulin response. They repeated this ipGTT in ghrelin knockout animals and, under these conditions, GO-CoA-Tat did not have a significant effect compared either with vehicle or with its impact on WT animals (33). Apparently, GO-CoA-Tat's effects on glucose regulation are mediated by acyl ghrelin inhibition. 
Another report on the potential beneficial effects of antagonizing AG showed that the ghrelin receptor antagonist [D-Lys3]-GHRP-6, after 7 days of subcutaneous treatment, markedly decreased food intake in ovariectomized mice fed both high-fat and standard diets. Furthermore, Maletinska et al. (34) reported that this AG antagonist reduced body weight, blood glucose, insulin, and leptin.

\section{In vivo results in humans}

Benso et al. (35) recently reported that i.v. DAG administration improves glucose metabolism and inhibits lipolysis in healthy volunteers. Apparently, and in contrast to the diabetogenic action of AG, DAG displays hypoglycemic properties.

They studied the effects of a 16-h overnight infusion of DAG or saline in eight normal subjects. The overall insulin levels (as AUC) were not significantly modified by DAG infusion. However, postprandial insulin levels after both dinner and breakfast were significantly increased following DAG treatment compared with placebo.

We recently performed a clinical study in eight overweight patients with controlled type 2 diabetes on the effects of a continuous overnight infusion of two doses of DAG vs placebo in a double blind crossover study on AG concentrations and the glucose and insulin responses to a standard breakfast meal (SBM).

Early morning AG levels (during the overnight DAG infusion, just before the SBM) dropped significantly. DAG administration also markedly decreased AG levels following breakfast.

Moreover, overnight infusions of DAG significantly decreased postprandial glucose levels after the SBM (using continuous glucose monitoring, as well as peak serum glucose levels). There was a strong correlation between fasting AG levels and the magnitude of suppression of postprandial glucose levels by DAG administration. The higher the fasting AG levels, the more pronounced the decrease in glucose levels. This close correlation between the effect of DAG infusion on postprandial glycemia and the preprandial AG levels suggests a potential clinical benefit of DAG administration, especially in subjects with relatively high levels of $\mathrm{AG}$.

The concept that low AG/DAG ratios are accompanied by an improved metabolic state was supported by Cederberg et al. They reported that after 6 months of an intensive long-term physical exercise by 552 young men undergoing military service, improvements in body weight and body composition were associated with an increase in DAG (36). However, the samples in this study were collected in such a way that acyl ghrelin might easily convert to DAG, although this would be the case in both the baseline and the 6-month data (36).

\section{GHSR 1a- and ghrelin-independent effects of DAG}

Delhanty et al. studied the GHSR1a-independent effects of DAG in mice in vivo. Using microarrays, they examined rapid effects of DAG on genome-wide expression patterns in fat, muscle, and liver of GHSR1a-deficient mice. The expression data were analyzed using Ingenuity Pathways Analysis and Gene Set Enrichment Analysis. Regulation of subsets of these genes was verified by quantitative PCR in independent experiments. They found that DAG acutely regulated clusters of genes involved in glucose and lipid metabolism in all three tissues, consistent with enhancement of insulin sensitivity. This pivotal set of studies demonstrates that DAG rapidly modulates the expression of metabolically important genes in these tissues, which are central to the control of lipid and glucose homeostasis. These results strongly indicate a direct, GHSR 1a-independent, action of DAG that improves insulin sensitivity and metabolic profile (5).

Gauna et al. (37) reported the results of a study on the interactions between AG and DAG on ghrelin receptors in INS-1E rat insulinoma cells, using insulin secretion after 30-min static incubation as a read-out. Both DAG and AG dose dependently stimulated insulin release in the nanomolar range. As expected, the AG-induced insulin output was antagonized by the two GHSR1a antagonists [D-Lys3]-GHRP-6 and BIM28163. These GHSR1a blockers, however, did not block DAG-induced insulin secretion. These data strongly suggest the existence of a specific receptor for DAG, other than the GHS-R1a, that DAG might share with AG.

Halem et al. in 2005 (38) also reported on the potential presence of a non-GHSR 1a. They demonstrated that the GHSR1a blocker BIM-28163 that was also used in the Gauna study above blocked AG activation of the GHSR $1 \mathrm{a}$ and inhibited AG-induced GH secretion in vivo. To their surprise, they observed that BIM-28163 also acted as an agonist with regard to stimulating weight gain. Again Halem's results suggest the presence of an unknown ghrelin receptor that modulates ghrelin actions on weight gain (38). The great clinical importance of these studies is the notion that GHSR1 a may not be the most appropriate target for antiobesity strategies. An example of this is a report by Chen et al. (39) who observed a potential role for the CRF type 2 receptor in DAG's action in regulating food intake.

\section{Non-metabolic actions of AG and DAG}

Intriguing reports have appeared recently showing that AG and DAG have effects on several non-metabolic conditions. An example of this is a study by Sheriff $e t$ al. They observed that DAG exhibits pro-anabolic and anticatabolic effects on $\mathrm{C} 2 \mathrm{C} 12$ myotubes exposed to 
cytokines and reduces burn-induced muscle proteolysis in rats $(40)$.

Another study on the effects of DAG suggests that it can rescue endothelial progenitor cell (EPC) function in individuals with type 2 diabetes (41). Togliatto et al. investigated the potential of DAG to reverse diabetesassociated pathologies in individuals with type 2 diabetes, and $o b / o b$ mice. Systemic administration of DAG, but not AG, prevented diabetes-induced damage to EPCs by modulating the NADPH oxidase regulatory protein Rac1 and improved vasculogenic potential both in individuals with type 2 diabetes and in $o b / o b$ mice. In addition, unlike AG, DAG facilitated the recovery of bone marrow EPC mobilization (41).

In line with this, a recent report by Zhang et al. (42) reported that low (total) ghrelin levels are closely associated with severity and morphology of angiographically detected coronary atherosclerosis in patients with diabetes mellitus.

Moreover, Yang et al. (43) studied the effect of ghrelin on angiotensin II (Ang II)-induced apoptosis of H9c2 cardiomyocytes. The results showed that ghrelin prevents Ang II-induced H9c2 cell death. Their data suggest that ghrelin may play an antagonistic role in Ang IIinduced cardiomyocyte apoptosis by decreasing angiotensin receptor expression and inhibiting activation of the endoplasmic reticulum stress pathway (43).

Wu et al. (44) reported that ghrelin maintains the cardiovascular stability in severe sepsis. In their study, male adult rats were made septic by cecal ligation and puncture (CLP). At $5 \mathrm{~h}$ after CLP, a bolus i.v. injection of ghrelin was followed by continuous infusion of $12 \mathrm{nmol}$ ghrelin via a primed mini-pump for $15 \mathrm{~h}$. Treatment with ghrelin significantly augmented the maximal rates of ventricular pressure increase and decrease by 36 and $35 \%$ respectively. Ghrelin treatment also reversed the suppression of norepinephrine-induced vascular contraction and acetylcholine-induced endotheliumdependent vascular relaxation caused by CLP (44).

Another unexpected link between the ghrelin system and a clinical condition is that ghrelin only very recently has been introduced into the field of epilepsy and has already led to contradictory clinical publications. In humans, AG and DAG, on the whole, are found to decrease following an epileptic seizure. Furthermore, the majority of animal studies on this subject demonstrate that ghrelin has anticonvulsant properties, but very little is known about the mechanisms by which ghrelin inhibits seizures. A recent valuable review by Portelli et al. addresses possible mechanisms of action for both AG (and DAG) in the prevention of seizures and indirectly gives an insight into modes of action of these peptides for researchers studying ghrelin in other fields of research (45).

Finally, the ghrelin system is also linked to gonadal function $(46,47)$, gut motility $(39,48,49$, 50), and cancer $(51,52,53,54)$, and it is highly likely that this relatively new hormone family will be linked to other medical conditions in the near future.

\section{Conclusion}

In conclusion, DAG is more than just a degradation product of acyl ghrelin. It appears to be a separate hormone, with its own actions, independent from the actions of ghrelin. DAG can only bind and activate the GHSR 1a at supra-physiological concentrations. This low affinity interaction rules out the GHSR1a as a mediator of DAG activities at physiological concentrations. Increased AG/DAG ratios are linked to obesity and diabetes. An important caveat to interpretation of the available data, however, is that some of the reported studies did not measure directly DAG. DAG administration induces a rapid decrease in circulating AG levels, along with an improvement in glycemic control.

The insight that DAG can antagonize AG via several routes and should be considered as a natural antagonist of ghrelin could lead to the development of ghrelin inhibitors that might be helpful in the treatment of conditions in which high AG (actions) are linked with the severity of the disease, as in, e.g. PWS patients and in obese type 2 diabetes subjects.

\section{Declaration of interest}

P J D Delhanty and S J Neggers declare that there is no conflict of interest that could be perceived as prejudicing the impartiality of the review reported. A J van der Lely is scientific advisor and shareholder of Alizé Pharma SAS, Ecully, France.

\section{Funding}

This review did not receive any specific grant from any funding agency in the public, commercial or not-for-profit sector.

\section{References}

1 Kojima M, Hosoda H, Date $\mathrm{Y}$, Nakazato M, Matsuo H \& Kangawa K. Ghrelin is a growth-hormone-releasing acylated peptide from stomach. Nature 1999402 656-660. (doi:10.1038/ 45230)

2 Koyama KI, Yasuhara D, Nakahara T, Harada T, Uehara M, Ushikai M, Asakawa A \& Inui A. Changes in acyl ghrelin, des-acyl ghrelin, and ratio of acyl ghrelin to total ghrelin with short-term refeeding in female inpatients with restricting-type anorexia nervosa. Hormone and Metabolic Research 201042 595-598. (doi:10.1055/s-0030-1252017)

3 Gutierrez JA, Solenberg PJ, Perkins DR, Willency JA, Knierman MD, Jin Z, Witcher DR, Luo S, Onyia JE \& Hale JE. Ghrelin octanoylation mediated by an orphan lipid transferase. PNAS 2008105 6320-6325. (doi:10.1073/pnas.0800708105)

4 Yang J, Brown MS, Liang G, Grishin NV \& Goldstein JL. Identification of the acyltransferase that octanoylates ghrelin, an appetite-stimulating peptide hormone. Cell 2008132 387-396. (doi:10.1016/j.cell.2008.01.017)

5 Delhanty PJ, Sun Y, Visser JA, van Kerkwijk A, Huisman M, van Ijcken WF, Swagemakers S, Smith RG, Themmen AP \& van der Lely AJ. Unacylated ghrelin rapidly modulates lipogenic and insulin signaling pathway gene expression in metabolically active tissues of GHSR deleted mice. PLoS ONE 20105 e11749. (doi:10.1371/journal.pone.0011749) 
6 Kang K, Schmahl J, Lee JM, Garcia K, Patil K, Chen A, Keene M, Murphy A \& Sleeman MW. Mouse ghrelin-O-acyltransferase (GOAT) plays a critical role in bile acid reabsorption. FASEB Journal 201226 259-271. (doi:10.1096/fj.11-191460)

7 Gauna C, van de Zande B, van Kerkwijk A, Themmen AP, van der Lely AJ \& Delhanty PJ. Unacylated ghrelin is not a functional antagonist but a full agonist of the type 1a growth hormone secretagogue receptor (GHS-R). Molecular and Cellular Endocrinology 2007274 30-34. (doi:10.1016/j.mce.2007.05.010)

8 Longo KA, Charoenthongtrakul S, Giuliana DJ, Govek EK, McDonagh T, Qi Y, DiStefano PS \& Geddes BJ. Improved insulin sensitivity and metabolic flexibility in ghrelin receptor knockout mice. Regulatory Peptides 2008150 55-61. (doi:10.1016/j. regpep.2008.03.011)

9 Nonogaki K, Nozue K \& Oka Y. Hyperphagia alters expression of hypothalamic 5-HT2C and 5-HT1B receptor genes and plasma des-acyl ghrelin levels in Ay mice. Endocrinology 2006 147 5893-5900. (doi:10.1210/en.2006-0418)

10 Pacifico L, Poggiogalle E, Costantino F, Anania C, Ferraro F, Chiarelli F \& Chiesa C. Acylated and nonacylated ghrelin levels and their associations with insulin resistance in obese and normal weight children with metabolic syndrome. European Journal of Endocrinology 2009161 861-870. (doi:10.1530/EJE-09-0375)

11 St-Pierre DH, Karelis AD, Coderre L, Malita F, Fontaine J, Mignault D, Brochu M, Bastard JP, Cianflone K, Doucet E, Imbeault P \& Rabasa-Lhoret R. Association of acylated and nonacylated ghrelin with insulin sensitivity in overweight and obese postmenopausal women. Journal of Clinical Endocrinology and Metabolism 2007 92 264-269. (doi:10.1210/jc.2006-1603)

12 Barazzoni R, Zanetti M, Ferreira C, Vinci P, Pirulli A, Mucci M, Dore F, Fonda M, Ciocchi B, Cattin L \& Guarnieri G. Relationships between desacylated and acylated ghrelin and insulin sensitivity in the metabolic syndrome. Journal of Clinical Endocrinology and Metabolism 200792 3935-3940. (doi:10.1210/jc.2006-2527)

13 Rodriguez A, Gomez-Ambrosi J, Catalan V, Gil MJ, Becerril S, Sainz N, Silva C, Salvador J, Colina I \& Fruhbeck G. Acylated and desacyl ghrelin stimulate lipid accumulation in human visceral adipocytes. International Journal of Obesity 200933 541-552. (doi:10.1038/ijo.2009.40)

14 Purtell L, Sze L, Loughnan G, Smith E, Herzog H, Sainsbury A, Steinbeck K, Campbell LV \& Viardot A. In adults with Prader-Willi syndrome, elevated ghrelin levels are more consistent with hyperphagia than high PYY and GLP-1 levels. Neuropeptides 201145 301-307. (doi:10.1016/j.npep.2011.06.001)

15 Goldstone AP, Holland AJ, Butler JV \& Whittington JE. Appetite hormones and the transition to hyperphagia in children with Prader-Willi syndrome. International Journal of Obesity 2012. In press. (doi:10.1038/ijo.2011.274)

16 Broglio F, Gottero C, Prodam F, Gauna C, Muccioli G, Papotti M, Abribat T, van der Lely AJ \& Ghigo E. Non-acylated ghrelin counteracts the metabolic but not the neuroendocrine response to acylated ghrelin in humans. Journal of Clinical Endocrinology and Metabolism 200489 3062-3065. (doi:10.1210/jc.2003031964)

17 Inhoff T, Monnikes H, Noetzel S, Stengel A, Goebel M, Dinh QT, Riedl A, Bannert N, Wisser AS, Wiedenmann B, Klapp BF, Tache Y \& Kobelt P. Desacyl ghrelin inhibits the orexigenic effect of peripherally injected ghrelin in rats. Peptides $2008 \mathbf{2 9}$ 2159-2168. (doi:10.1016/j.peptides.2008.09.014)

18 Neary NM, Druce MR, Small CJ \& Bloom SR. Acylated ghrelin stimulates food intake in the fed and fasted states but desacylated ghrelin has no effect. Gut $2006 \mathbf{5 5} 135$.

19 Kumar R, Salehi A, Rehfeld JF, Hoglund P, Lindstrom E \& Hakanson R. Proghrelin peptides: desacyl ghrelin is a powerful inhibitor of acylated ghrelin, likely to impair physiological effects of acyl ghrelin but not of obestatin A study of pancreatic polypeptide secretion from mouse islets. Regulatory Peptides 2010 164 65-70. (doi:10.1016/j.regpep.2010.06.005)

20 Gauna C, Meyler FM, Janssen JA, Delhanty PJ, Abribat T, van Koetsveld P, Hofland LJ, Broglio F, Ghigo E \& van der Lely AJ. Administration of acylated ghrelin reduces insulin sensitivity, whereas the combination of acylated plus unacylated ghrelin strongly improves insulin sensitivity. Journal of Clinical Endocrinology and Metabolism 200489 5035-5042. (doi:10.1210/jc. 2004-0363)

21 Granata R, Settanni F, Biancone L, Trovato L, Nano R, Bertuzzi F, Destefanis S, Annunziata M, Martinetti M, Catapano F, Ghe C, Isgaard J, Papotti M, Ghigo E \& Muccioli G. Acylated and unacylated ghrelin promote proliferation and inhibit apoptosis of pancreatic $\beta$-cells and human islets: involvement of $3^{\prime}, 5^{\prime}$-cyclic adenosine monophosphate/protein kinase A, extracellular signalregulated kinase $1 / 2$, and phosphatidyl inositol 3-kinase/Akt signaling. Endocrinology $2007 \mathbf{1 4 8} 512-529$. (doi:10.1210/en. 2006-0266)

22 Gauna C, Delhanty PJ, Hofland LJ, Janssen JA, Broglio F, Ross RJ, Ghigo E \& van der Lely AJ. Ghrelin stimulates, whereas desoctanoyl ghrelin inhibits, glucose output by primary hepatocytes. Journal of Clinical Endocrinology and Metabolism $2005 \mathbf{9 0}$ 1055-1060. (doi:10.1210/jc.2004-1069)

23 Miegueu P, St Pierre D, Broglio F \& Cianflone K. Effect of desacyl ghrelin, obestatin and related peptides on triglyceride storage, metabolism and GHSR signaling in 3T3-L1 adipocytes. Journal of Cellular Biochemistry $2011 \mathbf{1 1 2}$ 704-714. (doi:10.1002/jcb. 22983)

24 Depoortere I, Thijs T \& Peeters T. The contractile effect of the ghrelin receptor antagonist, D-Lys3-GHRP-6, in rat fundic strips is mediated through 5-HT receptors. European Journal of Pharmacology 2006537 160-165. (doi:10.1016/j.ejphar.2006.03.043)

25 Schioth HB, Muceniece R \& Wikberg JE. Characterization of the binding of MSH-B, HB-228, GHRP-6 and 153N-6 to the human melanocortin receptor subtypes. Neuropeptides 199731 565-571. (doi:10.1016/S0143-4179(97)90002-0)

26 Muccioli G, Pons N, Ghe C, Catapano F, Granata R \& Ghigo E. Ghrelin and des-acyl ghrelin both inhibit isoproterenol-induced lipolysis in rat adipocytes via a non-type 1a growth hormone secretagogue receptor. European Journal of Pharmacology 2004498 27-35. (doi:10.1016/j.ejphar.2004.07.066)

27 Baragli A, Ghe C, Arnoletti E, Granata R, Ghigo E \& Muccioli G. Acylated and unacylated ghrelin attenuate isoproterenol-induced lipolysis in isolated rat visceral adipocytes through activation of phosphoinositide 3-kinase $\gamma$ and phosphodiesterase 3B. Biochimica et Biophysica Acta $2011 \mathbf{1 8 1 1}$ 386-396. (doi:10.1016/j.bbalip. 2011.03.001)

28 Lear PV, Iglesias MJ, Feijoo-Bandin S, Rodriguez-Penas D, Mosquera-Leal A, Garcia-Rua V, Gualillo O, Ghe C, Arnoletti E, Muccioli G, Dieguez C, Gonzalez-Juanatey JR \& Lago F. Des-acyl ghrelin has specific binding sites and different metabolic effects from ghrelin in cardiomyocytes. Endocrinology 2010151 3286-3298. (doi:10.1210/en.2009-1205)

29 Moazed B, Quest D \& Gopalakrishnan V. Des-acyl ghrelin fragments evoke endothelium-dependent vasodilatation of rat mesenteric vascular bed via activation of potassium channels. European Journal of Pharmacology 2009 604 79-86. (doi:10.1016/ j.ejphar.2008.10.032)

30 Asakawa A, Inui A, Fujimiya M, Sakamaki R, Shinfuku N, Ueta Y, Meguid MM \& Kasuga M. Stomach regulates energy balance via acylated ghrelin and desacyl ghrelin. Gut $2005 \mathbf{5 4} 18-24$. (doi:10.1136/gut.2004.038737)

31 Zhang W, Chai B, Li JY, Wang H \& Mulholland MW. Effect of desacyl ghrelin on adiposity and glucose metabolism. Endocrinology 2008 149 4710-4716. (doi:10.1210/en.2008-0263)

32 Martens K, Bottelbergs A \& Baes M. Ectopic recombination in the central and peripheral nervous system by aP2/FABP4-Cre mice: implications for metabolism research. FEBS Letters $2010 \mathbf{5 8 4}$ 1054-1058. (doi:10.1016/j.febslet.2010.01.061)

33 Barnett BP, Hwang Y, Taylor MS, Kirchner H, Pfluger PT, Bernard V, Lin YY, Bowers EM, Mukherjee C, Song WJ, Longo PA, Leahy DJ, Hussain MA, Tschop MH, Boeke JD \& Cole PA. Glucose and weight control in mice with a designed ghrelin O-acyltransferase inhibitor. Science $2010 \quad 330$ 1689-1692. (doi:10.1126/science.1196154) 
34 Maletinska L, Matyskova R, Maixnerova J, Sykora D, Pychova M, Spolcova A, Blechova M, Drapalova J, Lacinova Z, Haluzik M \& Zelezna B. The peptidic GHS-R antagonist [D-Lys(3)]GHRP-6 markedly improves adiposity and related metabolic abnormalities in a mouse model of postmenopausal obesity. Molecular and Cellular Endocrinology 2011343 55-62. (doi:10.1016/j.mce.2011.06.006)

35 Benso A, St-Pierre D, Prodam F, Gramaglia E, Granata R, Van der Lely AJ, Ghigo E \& Broglio F. Metabolic effects of overnight continuous infusion of unacylated ghrelin in humans. European Journal of Endocrinology 2012166 911-916. (doi:10.1530/EJE11-0982)

36 Cederberg H, Rajala U, Koivisto VM, Jokelainen J, Surcel HM, Keinanen-Kiukaanniemi S \& Laakso M. Unacylated ghrelin is associated with changes in body composition and body fat distribution during long-term exercise intervention. European Journal of Endocrinology 2011165 243-248. (doi:10.1530/EJE11-0334)

37 Gauna C, Delhanty PJ, van Aken MO, Janssen JA, Themmen AP, Hofland LJ, Culler M, Broglio F, Ghigo E \& van der Lely AJ. Unacylated ghrelin is active on the INS-1E rat insulinoma cell line independently of the growth hormone secretagogue receptor type $1 \mathrm{a}$ and the corticotropin releasing factor 2 receptor. Molecular and Cellular Endocrinology 2006251 103-111. (doi:10.1016/j.mce. 2006.03.040)

38 Halem HA, Taylor JE, Dong JZ, Shen Y, Datta R, Abizaid A, Diano S, Horvath TL \& Culler MD. A novel growth hormone secretagogue-1a receptor antagonist that blocks ghrelin-induced growth hormone secretion but induces increased body weight gain. Neuroendocrinology 200581 339-349. (doi:10.1159/ 000088796)

39 Chen CY, Inui A, Asakawa A, Fujino K, Kato I, Chen CC, Ueno N \& Fujimiya M. Des-acyl ghrelin acts by CRF type 2 receptors to disrupt fasted stomach motility in conscious rats. Gastroenterology 2005129 8-25. (doi:10.1053/j.gastro.2005.04.015)

40 Sheriff S, Kadeer N, Joshi R, Friend LA, James JH \& Balasubramaniam A. Des-acyl ghrelin exhibits pro-anabolic and anti-catabolic effects on $\mathrm{C} 2 \mathrm{C} 12$ myotubes exposed to cytokines and reduces burn-induced muscle proteolysis in rats. Molecular and Cellular Endocrinology 2012351 286-295. (doi:10.1016/j. mce.2011.12.021)

41 Togliatto G, Trombetta A, Dentelli P, Baragli A, Rosso A, Granata R, Ghigo D, Pegoraro L, Ghigo E \& Brizzi MF. Unacylated ghrelin rescues endothelial progenitor cell function in individuals with type 2 diabetes. Diabetes 201059 1016-1025. (doi:10. 2337/db09-0858)

42 Zhang M, Fang WY, Yuan F, Qu XK, Liu H, Xu YJ, Chen H, Yu YF, Shen Y \& Zheng ZC. Plasma ghrelin levels are closely associated with severity and morphology of angiographically-detected coronary atherosclerosis in Chineses patients with diabetes mellitus. Acta Pharmacologica Sinica 201233 452-458. (doi:10. 1038/aps.2011.196)

43 Yang C, Wang Y, Liu H, Li N, Sun Y, Zhonghui L \& Ping Y. Ghrelin protects $\mathrm{H} 9 \mathrm{c} 2$ cardiomyocytes from angiotensin II-induced apoptosis through the endoplasmic reticulum stress pathway. Journal of Cardiovascular Pharmacology 201259 465-471. (doi:10. 1097/FJC.0b013e31824a7b60)

$44 \mathrm{Wu} \mathrm{R}$, Chaung WW, Dong W, Ji Y, Barrera R, Nicastro J, Molmenti EP, Coppa GF \& Wang P. Ghrelin maintains the cardiovascular stability in severe sepsis. Journal of Surgical Research 2012. In press. (doi:10.1016/j.jss.2011.12.021)

45 Portelli J. Michotte Y \& Smolders I. Ghrelin: an emerging new anticonvulsant neuropeptide. Epilepsia 201253 585-595. (doi:10.1111/j.1528-1167.2012.03423.x)

46 Tena-Sempere M. Ghrelin and reproduction: ghrelin as novel regulator of the gonadotropic axis. Vitamins and Hormones 2007 77 285-300. (doi:10.1016/S0083-6729(06)77012-1)
47 Tena-Sempere M. Ghrelin as a pleotrophic modulator of gonadal function and reproduction. Nature Clinical Practice. Endocrinology and Metabolism 20084 666-674. (doi:10.1038/ncpendmet1003) 48 Asakawa A, Ataka K, Fujino K, Chen CY, Kato I, Fujimiya M \& Inui A. Ghrelin family of peptides and gut motility. Journal of Gastroenterology and Hepatology 201126 (Suppl 3) 73-74. (doi:10.1111/j.1440-1746.2011.06638.x)

49 Chen CY \& Huang SC. Lack of direct effects of acyl ghrelin, des-acyl ghrelin, and obestatin on rat lower esophageal sphincter motility in vitro. Journal of the Chinese Medical Association 2011 74 394-399. (doi:10.1016/j.jcma.2011.08.003)

50 Ogiso K, Asakawa A, Amitani H \& Inui A. Ghrelin: a gut hormonal basis of motility regulation and functional dyspepsia. Journal of Gastroenterology and Hepatology 201126 (Suppl 3) 67-72. (doi:10.1111/j.1440-1746.2011.06630.x)

$51 \mathrm{Lu}$ C, McFarland MS, Nesbitt RL, Williams AK, Chan S, GomezLemus J, Autran AM, Al-Zahrani A, Chin JL, Izawa JI, Luyt LG \& Lewis JD. Ghrelin receptor as a novel imaging target for prostatic neoplasms. Prostate 201272 825-833. (doi:10.1002/pros. 21484)

52 Murphy G, Kamangar F, Dawsey SM, Stanczyk FZ, Weinstein SJ, Taylor PR, Virtamo J, Abnet CC, Albanes D \& Freedman ND. The relationship between serum ghrelin and the risk of gastric and esophagogastric junctional adenocarcinomas. Journal of the National Cancer Institute 2011103 1123-1129. (doi:10.1093/ jnci/djr194)

53 Gronberg M, Fjallskog ML, Jirstrom K \& Janson ET. Expression of ghrelin is correlated to a favorable outcome in invasive breast cancer. Acta Oncologica $2012 \mathbf{5 1}$ 386-393. (doi:10.3109/ 0284186X.2011.631576)

54 Chopin L, Walpole C, Seim I, Cunningham P, Murray R, Whiteside E, Josh P \& Herington A. Ghrelin and cancer. Molecular and Cellular Endocrinology 2011340 65-69. (doi:10.1016/j.mce. 2011.04.013)

55 Granata R, Settanni F, Julien M, Nano R, Togliatto G, Trombetta A, Gallo D, Piemonti L, Brizzi MF, Abribat T, van Der Lely AJ \& Ghigo E. Des-acyl ghrelin fragments and analogues promote survival of pancreatic $\beta$-cells and human pancreatic islets and prevent diabetes in streptozotocin-treated rats. Journal of Medicinal Chemistry $2012 \mathbf{5 5}$ 2585-2596. (doi:10.1021/ jm201223m)

56 Granata R, Settanni F, Trovato L, Destefanis S, Gallo D, Martinetti M, Ghigo E \& Muccioli G. Unacylated as well as acylated ghrelin promotes cell survival and inhibit apoptosis in HIT-T1 5 pancreatic $\beta$-cells. Journal of Endocrinological Investigation 200629 RC19-RC22.

57 Broglio F, Gottero C, Prodam F, Gauna C, Muccioli G, Papotti M, Abribat T, van der Lely AJ \& Ghigo E. Non-acylated ghrelin counteracts the metabolic but not the neuroendocrine response to acylated ghrelin in humans. Journal of Clinical Endocrinology \& Metabolism 200489 3062-3065. (doi:10.1210/jc.2003031964)

58 Gauna C, Meyler FM, Janssen J, Delhanty PJD, Abribat T, Van Koetsveld P, Hofland LJ, Broglio F, Ghigo E \& van der Lely AJ. Administration of acylated ghrelin reduces insulin sensitivity, whereas the combination of acylated plus unacylated ghrelin strongly improves insulin sensitivity. Journal of Clinical Endocrinology and Metabolism 200489 5035-5042. (doi:10. $1210 /$ jc.2004-0363)

Received 25 May 2012

Revised version received 15 August 2012

Accepted 16 August 2012 